Article

\title{
An Experimental Investigation on the Effects of Limestone Fines in Manufactured Sands on the Performance of Magnesia Ammonium Phosphate Mortar
}

\author{
Wenting Mao ${ }^{1, *} \mathbb{C}$, Chunpeng Cao ${ }^{1}$, Xincheng $\mathrm{Li}^{1, *}$, Jueshi Qian ${ }^{2}$ and Yudong Dang ${ }^{1} \mathbb{D}$ \\ 1 Yunnan Academy of Building Research Co., Ltd., Kunming Economic and Technological Development Area, \\ China (Yunnan) Pilot Free Trade Zone, Kunming 650231, China; caochpeng@163.com (C.C.); \\ yddang@163.com (Y.D.) \\ 2 College of Materials Science and Engineering, Chongqing University, No. 174 Shazhengjie, Shapingba, \\ Chongqing 400044, China; qianjueshi@126.com \\ * Correspondence: wm280@alumni.cam.ac.uk (W.M.); xinchengli@aliyun.com (X.L.)
}

check for updates

Citation: Mao, W.; Cao, C.; Li, X.; Qian, J.; Dang, Y. An Experimental Investigation on the Effects of Limestone Fines in Manufactured Sands on the Performance of Magnesia Ammonium Phosphate Mortar. Buildings 2022, 12, 249. https://doi.org/10.3390/ buildings12020249

Academic Editor: Jorge de Brito

Received: 11 January 2022

Accepted: 14 February 2022

Published: 21 February 2022

Publisher's Note: MDPI stays neutral with regard to jurisdictional claims in published maps and institutional affiliations.

Copyright: (C) 2022 by the authors. Licensee MDPI, Basel, Switzerland. This article is an open access article distributed under the terms and conditions of the Creative Commons Attribution (CC BY) license (https:// creativecommons.org/licenses/by/ $4.0 /)$.

\begin{abstract}
Magnesium ammonium phosphate cement (MAPC) prepared with ammonium dihydrogen phosphate $\left(\mathrm{NH}_{4} \mathrm{H}_{2} \mathrm{PO}_{4}, \mathrm{ADP}\right)$ and dead-burned Magnesium oxide $(\mathrm{MgO})$ is a new type of rapid patch repair material for concrete structures. In order to reduce the material costs of MAPC mortar, manufactured limestone sands, being a more widely-available resource with lower cost, was investigated in this study as an alternative to quartz sands for the preparation of MAPC mortar. The limestone fines in manufactured sands were found to be the key factor that influences properties of MAPC mortar by causing bubbling and volume expansion before hardening. As a result, the mechanical strength of MAPC mortar decreased with the increasing content of limestone fines due to increased porosity. According to microstructure analysis, the mechanism of these negative effects can be inferred as the reaction between limestone fines and ADP with the gas generation of $\mathrm{CO}_{2}$ and $\mathrm{NH}_{3}$. This reaction mainly occurred during a short period before setting while most limestone fines remained unreactive in the hardened MAPC mortar. Based on the above detailed experimental findings on the effects of limestone fines in manufactured sand on the properties of MAPC mortar, this paper pointed out that effective defoaming methods for inhibiting bubbling was the key to the utilization of manufactured sands in preparation of high performance MAPC mortar.
\end{abstract}

Keywords: magnesium ammonium phosphate mortar; limestone fines; manufactured limestone sands; bubbling; volume expansion

\section{Introduction}

Maintenance work has always been the focus of concrete structures during longterm service life after construction. The structure damage accumulation and function degeneration due to load effects and environmental corrosion bring forward increasingly higher demands for repair technology [1-3]. Magnesia phosphate cement (MPC) has recently risen up as rapid repair material for concrete structures. It is a new type of a mineral binder formed by through-solution acid-based reaction between phosphate salt and dead-burnt magnesia (calcinated at a temperature above $1300{ }^{\circ} \mathrm{C}$ ) [4]. In contrast with ordinary Portland cementitious materials, MPC notably appears to have a fast hydration process, high early strength, good bonding at the repair interface, and good durability with low shrinkage and low permeability [1,4-8]. For such merits, MPC has received increasing attention in many fields during the last few decades of development as rapid repair to damaged concrete structures.

To produce MPC, ammonium dihydrogen phosphate $\left(\mathrm{NH}_{4} \mathrm{H}_{2} \mathrm{PO}_{4}, \mathrm{ADP}\right)$ or potassium dihydrogen phosphate $\left(\mathrm{KH}_{2} \mathrm{PO}_{4}, \mathrm{KDP}\right)$, as the commonly used phosphate salt, is mixed with calcined $\mathrm{MgO}$ and other fillers, such as fly ash [4,6,9]. ADP reacts with $\mathrm{MgO}$ to produce 
stable hydration products $\mathrm{NH}_{4} \mathrm{MgPO}_{4} \cdot 6 \mathrm{H}_{2} \mathrm{O}$ (Struvite), which constructs the matrix of magnesium ammonium phosphate cement (MAPC). MAPC has a controllable setting time through the use of retarders, such as borax $\left(\mathrm{NaB}_{4} \mathrm{O}_{7} \cdot 10 \mathrm{H}_{2} \mathrm{O}\right)$ and boric acid $\left(\mathrm{H}_{3} \mathrm{BO}_{3}\right)[5,10]$. The setting time can be flexibly adjusted from several to tens of minutes $[5,11]$, which meets the requirements of different application scenarios. As the setting time changes, the early strength development of MAPC was reported to vary in the range of 20-40 MPa for 1-h strength and reach over $45 \mathrm{MPa}$ at 3 days [12-14]. The hydration process is accompanied by the generation of small bubbles of $\mathrm{NH}_{3}$ [4]. Such a slight air-entraining effect is beneficial to improving the workability of MAPC mortar, which allows it to quickly fill in the repair area without vibration. When KDP is used, it is called magnesium potassium phosphate cement (MKPC). The hydration product of $\mathrm{MKPC}$ is $\mathrm{K}$-struvite $\left(\mathrm{MgKPO}_{4} \cdot 6 \mathrm{H}_{2} \mathrm{O}\right)$, which has a similar molecular structure and chemical properties to struvite [15]. MAPC has been considered to have greater potential in commercialization and scaled applications due to its relatively lower cost and higher early strength compared to other MPCs [5].

In field applications, MAPC are usually mixed with fine aggregates into MAPC mortar as repair compounds. More importantly, since magnesium oxide and phosphate react very quickly and generally release a large amount of heat, the incorporation of aggregates can help control the temperature rise to avoid overheat [12]. Typically, quartz sand is chosen to prepare MAPC mortar due to its high cleanliness and hardness and well gradation. However, high-quality quartz sand usually costs several times higher than natural river sand or manufactured limestone sand. This further increases the material cost of MAPC mortar. In recent years, manufactured limestone sand has been increasingly applied as fine aggregates for mortar and concrete production, due to the scarcity of river sand and concerns over environmental pollution. Manufactured limestone sand is widely available, renewable, and economic. Its use as a substitution is a cost-effective and sustainable way for the production and scaled applications of MAPC mortar, and also helps resolve the landfill of mine tailings or construction wastes.

Manufactured limestone sands have been widely reported to have a comparable performance for normal mortar and concrete production, such as controllable gradation, good interfacial bond, etc. [16-18]. However, the application of limestone sand in a MPC system is rarely reported. The relative high content of limestone fines, which refers to the fine particles that are less than $0.075 \mathrm{~mm}$, produced during the process of crushing limestone rocks into sands, is typical of manufactured limestone sand, compared with quartz sand and river sand. A few researchers have investigated limestone fines as additive in MKPC. Yang et al. [19] investigated the properties of magnesium phosphate cement with limestone fines. They found that the addition of limestone fines improved the early hydration degree of MKPC with an increased crystallization degree and the amount of hydration products, resulting in high mechanical strength and low shrinkage. Nonetheless, Chong et al. [20] reported the negative influences of limestone fines on the water stability of MKPC materials. It was found that limestone fines affected the crystal growth of struvite-K and further increased the porosity and dissolution of the hydration production of MKPC, which decreased the water stability of MKPC. While for MAPC materials, there is few relevant studies and the effects of limestone fines are unclear.

This paper focused on the effects of limestone fines on the properties of MAPC mortar prepared with limestone sand, including the setting time, workability, mechanical strength, and long-term volume stability. Microstructure analyses were also carried out to understand the mechanism behind the effects of limestone fines through various techniques, such as X-ray diffraction (XRD), thermo-gravimetry analysis (TG), scanning electron microscopy (SEM), and mercury intrusion porosimetry (MIP). Based on the above results, this paper attempted to provide useful references for the prospective application of limestone sand in the production of cost-effective MAPC mortar. 


\section{Materials and Methods}

\subsection{Materials}

- Magnesium Ammonium Phosphate Cement (MAPC)

MAPC is prepared by admixtures of dead burned magnesia fines $(\mathrm{MgO})$, ammonium dihydrogen phosphate (ADP), retarder, and fly ash (FA). The $\mathrm{P} / \mathrm{M}$ (ADP to $\mathrm{MgO}$ ) ratio is $3 / 8$ and the dosage of retarder is $4 \%$ of the sum of ADP and MgO. Fly ash is used as a filler in the mix design and its proportion in the mixture of MAPC is $20 \%$. Dead burned $\mathrm{MgO}$ was produced by calcination of magnesite $\left(\mathrm{MgCO}_{3}\right)$ over $1700{ }^{\circ} \mathrm{C}$, with an average particle size (D50) of $10.4 \mu \mathrm{m}$ and a purity of $97 \%$. Ammonium dihydrogen phosphate (ADP) from Guizhou Magnesium Phosphate Materials Co., Ltd., Guiyang, China is industrial grade with an average particle size (D50) of $3.04 \mu \mathrm{m}$ and a purity over $98 \%$. Borax $\left(\mathrm{Na}_{2} \mathrm{~B}_{4} \mathrm{O}_{7} \cdot 10 \mathrm{H}_{2} \mathrm{O}\right)$, with a purity over $99 \%$, was used as a retarder.

- Manufactured Limestone Sand

The manufactured limestone sand was obtained from a local quarry in Yuxi, Yunnan province. Five groups of limestone sand with different contents of limestone fines $(<0.075 \mathrm{~mm})$ at $0 \%, 5 \%, 10 \%, 15 \%$, and $20 \%$ were prepared. The chemical contents of limestone fines were also tested, which mainly consists of $\mathrm{CaCO}_{3}$ (89.93\%). The average particle size (D50) of limestone fines is $11.4 \mu \mathrm{m}$, which was measured by the Mastersizer 3000 of Malvern Panalytical. The quartz sand used is ISO standard sand with a maximum particle size of $2.36 \mathrm{~mm}$, obtained from China ISO Sand Co., Ltd., Xiamen, China.

\subsection{Preparation of MAPC Mortar}

Six mix groups were prepared for testing, including the control group with quartz sand and other five groups with limestone sand containing different contents of limestone fines. The MAPC mortar was prepared with MAPC and limestone sand at a mix ratio of 1:1. The water to binder ratio (mwater/mMAPC) was 0.16 . MAPC powders and the sand were firstly dry mixed for $60 \mathrm{~s}$ in the planetary mixer. After the addition of water, the mixture was wet mixed for another $90 \mathrm{~s}$.

The properties of each fresh mortar mix (fluidity, setting time, and hydration heat) were tested immediately after mixing. For the hardened properties, the MAPC mortar was cast in various molds and demolded after $30 \mathrm{~min}$, then continued to be cured at a standard laboratory environment $\left(20^{\circ} \mathrm{C}, 50 \% \mathrm{RH}\right)$ for mechanical strength tests and volume stability tests.

\subsection{Properties of MAPC Mortar with Limestone Sand}

- The Properties of Fresh Mortar

The fluidity of MAPC mortar was tested by the flow cone method according to the ASTM C939-10 standard [21]. The setting time was determined by the modified Vicat needle apparatus in accordance with the ASTM C187 standard [22]. Due to the initial setting time being very close to the final setting time in MAPC mortar, the initial setting time was usually taken to characterize its setting and hardening behavior.

\section{- Mechanical Strength}

The MAPC mortar samples were tested for compressive strength and flexural strength respectively at $1 \mathrm{~h}, 3 \mathrm{~h}, 3$ days, and 28 days according to the ISO 679 standard [23]. The cubes $(40 \mathrm{~mm} \times 40 \mathrm{~mm} \times 40 \mathrm{~mm}$ ) were tested for unconfined compressive strength (UCS) using a $300 \mathrm{kN}$ microcomputer-controlled electronic pressure testing machine at a loading rate of $2400 \mathrm{~N} / \mathrm{s}$. The prisms $(40 \mathrm{~mm} \times 40 \mathrm{~mm} \times 160 \mathrm{~mm})$ were tested for flexural strength at a loading rate of $50 \mathrm{~N} / \mathrm{s}$. Each group of samples were tested in triplicate and the average value was taken.

\section{- Volume Stability}

The volume stability of MAPC mortar was characterized by the linear deformation rate during early age before setting and later age after setting. The linear deformation of 
the MAPC mortar in fluid state before setting was measured using a graduated cylinder apparatus according to JTG 3420-2020 (T 0518-2020) [24], as shown in Figure 1. The mortar was cast into the cylinder immediately after mixing and the readings of level height were recorded every $30 \mathrm{~s}$ until $30 \mathrm{~min}$ after mixing. For the volume change after hardening, prisms $(25 \mathrm{~mm} \times 25 \mathrm{~mm} \times 280 \mathrm{~mm})$ were tested for linear deformation using a digital length comparator following the instruction of ASTM C596-18 [25]. The initial measurement was conducted immediately after demolding, and continued in the following 112 days. Three replicate samples were used for measurements of each mix group. The linear deformation rate $\Delta \mathrm{R}$ was calculated as in Equation (1).

$$
\mathrm{R}=100 \% \times\left(\mathrm{L}_{1}-\mathrm{L}_{0}\right) / \mathrm{L}_{0}
$$

where $L_{0}$ is the initial level height of fresh mortar or the initial length of the prism; $L_{1}$ is the level height of fresh mortar or the length of the prism at each curing age.

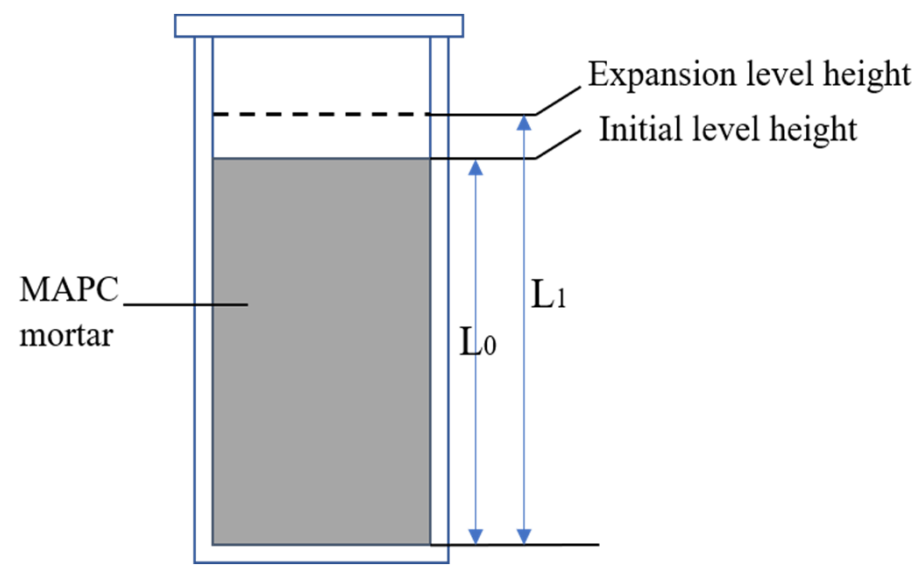

Figure 1. Testing apparatus of linear expansion of fresh MAPC mortar before setting.

\section{- Hydration Temperature}

The hydration process of MAPC is accompanied by significant exothermic phenomenon, especially during the initial few hours at the early age. The hydration temperature was tested by measuring the temperature variation inside the MAPC mortar samples. The temperature data were continuously recorded for $24 \mathrm{~h}$ through the sensor of the Elitech RC-4 temperature detector pre-cast in the middle of the sealed insulating container, as shown in Figure 2. The containers were placed in a stable laboratory environment with a temperature of $20{ }^{\circ} \mathrm{C}$ and relative humidity of $50 \%$.

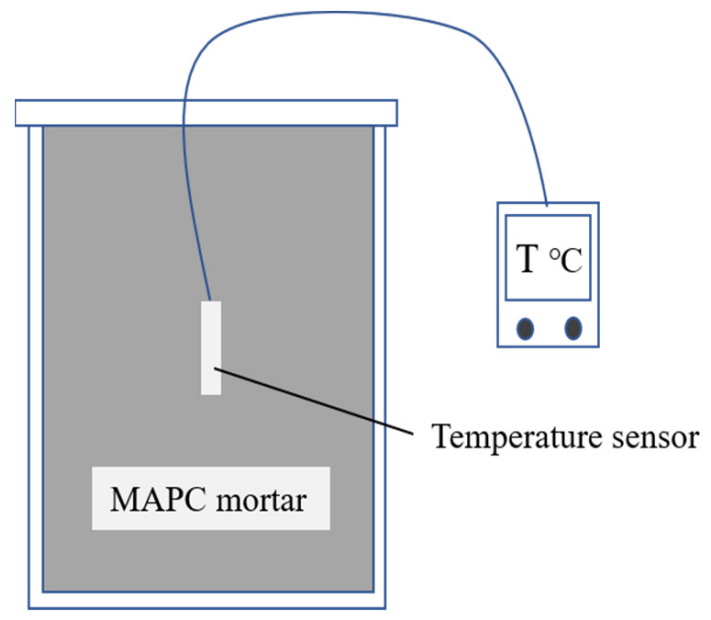

Figure 2. Testing apparatus of hydration temperature of MAPC during early age at $24 \mathrm{~h}$. 


\section{- Microstructure Analysis}

The fragments of MAPC mortar samples were collected for microstructure analysis. The collected fragments at specific ages were treated with absolute ethyl alcohol for terminating hydration and then dried in the oven at $40{ }^{\circ} \mathrm{C}$. The fragments after treatment were stored in the vacuum chamber until testing. For mercury intrusion porosimetry (MIP), cubic fragments in a size of $1 \mathrm{~cm} \times 1 \mathrm{~cm} \times 1 \mathrm{~cm}$ were prepared following the scheme as above and tested by MicroActive AutoPore V 9600. For thermo-gravimetry analysis (TG), the treated fragments were grounded into fines $(<45 \mu \mathrm{m})$ and then tested by METTLER TOLEDO TGA 1 at a heating rate of $10^{\circ} \mathrm{C}$ from 50 to $1000{ }^{\circ} \mathrm{C}$ in a nitrogen environment. The grounded fines of treated fragments were also analyzed by PANalytical $X^{\prime}$ Pert Powder $\mathrm{X}$-ray diffractometer using $\mathrm{Cu}-\mathrm{K} \alpha$ radiation $(40 \mathrm{kV} / 15 \mathrm{~mA})$ at a scanning rate of $0.02^{\circ} / \mathrm{s}$ in a $2 \theta$ range from $5^{\circ}$ to $60^{\circ}$. Additionally, the treated sample fragments were observed by SEM using TESCAN VEGA3 for the formation patterns of hydration products and the microstructures inside the matrix of the MAPC mortar.

\section{Results and Discission}

\subsection{Properties of Fresh MAPC Mortar}

As shown in Figure 3a, the increasing limestone fines content generally shows no significant effect on the fluidity of MAPC mortar, which fluctuated with a narrow range of 236-261 mm. As the limestone fines content increased from 0 to 5\%, the fluidity slightly grew from $240 \mathrm{~mm}$ to $261 \mathrm{~mm}$. However, when the limestone fines content further increased to $20 \%$, the fluidity showed a gradual decrease from $261 \mathrm{~mm}$ to $236 \mathrm{~mm}$. During the mixing, bubbling phenomenon was observed in groups with the presence of limestone fines. This may explain the slight increase of fluidity caused by the limestone fines at a low content of $5 \%$. In the meantime, limestone fines can also increase the water demand of MAPC mortar. As the content of limestone fines increased, the MAPC mortar became increasingly viscous, thereby decreasing the fluidity. Similarly, the setting time of MAPC mortar was barely influenced by the limestone fines, except for a slight shortening when the content increased to $20 \%$, as shown in Figure 3b. The setting time reflects the rate of the hydration process at an early age. However, a conclusion cannot be derived yet regarding whether the limestone fines will affect the hydration of MAPC. This requires further verification by hydration temperature analysis.

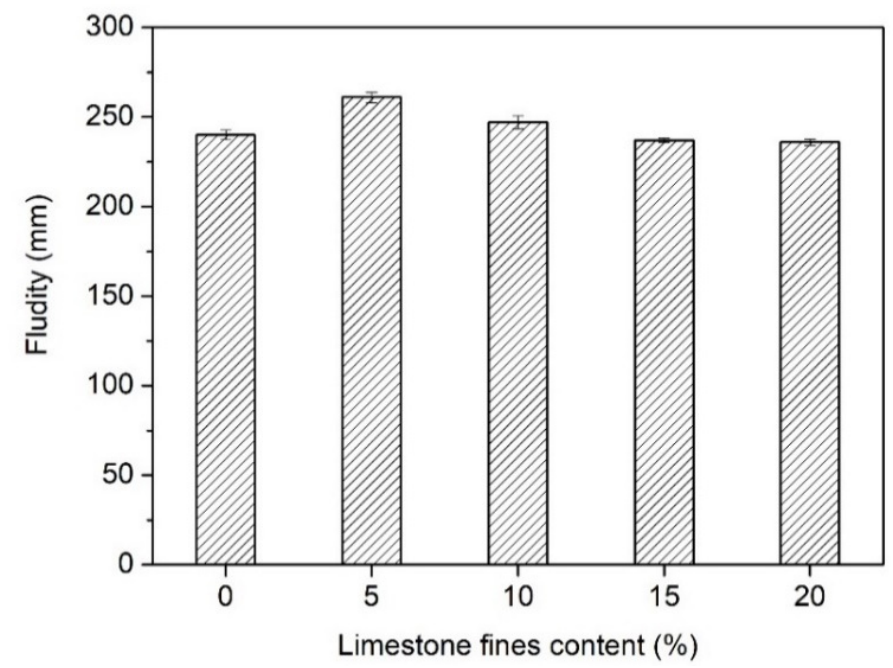

(a)

Figure 3. Cont. 


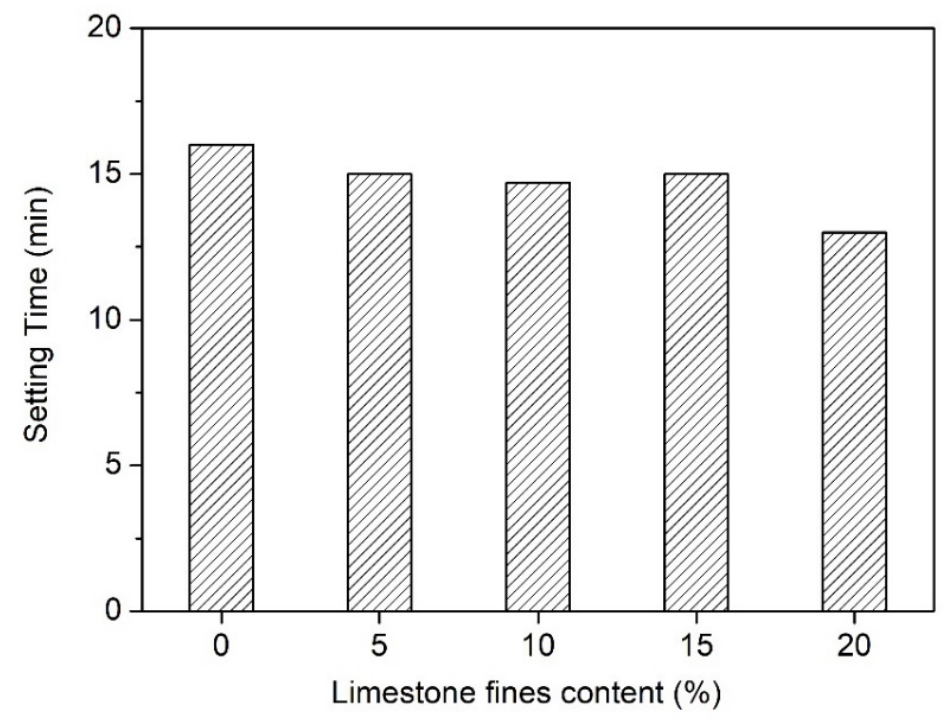

(b)

Figure 3. Fresh properties including the (a) fluidity and (b) setting time of MAPC mortar prepared by limestone sand with different contents of limestone fines ( $0-20 \%$ by weight of MAPC cement).

In addition, the control sample by quartz sand showed similar fluidity $(247 \mathrm{~mm})$ and setting time (16 $\mathrm{min}$ ) to the sample by limestone sand with $0 \%$ limestone fines. Without the effects of limestone fines, MAPC mortar by limestone sand generally showed comparable fresh properties with the one by quartz sand.

\subsection{Volume Stability of MAPC Mortar with Limestone Sand}

The volume change of MAPC mortar at an early age before the setting and later age were both tested. As shown in Figure 4a, significant expansion was observed in the groups of MAPC mortar containing limestone fines. The volume of MAPC mortar expanded dramatically with increasing limestone fines content during the early age of $10 \mathrm{~min}$ after mixing. Even a low content of limestone fines at $5 \%$ could induce a volume expansion of $5.94 \%$. The largest volume expansion of $8.2 \%$ was observed in the sample with $15 \%$ content of limestone fines. By contrast, the sample with $0 \%$ limestone fines and the control sample prepared by quartz sand showed only a slight expansion of less than $1 \%$. It was noticed that the expansion also sped up by increasing the limestone fines content. The higher content the limestone fines, the faster the expansion at an early age. The volume expansion could be due to a bubbling effect caused by limestone fines in the MAPC mortar. The reaction between $\mathrm{MgO}$ and $\mathrm{NH}_{4} \mathrm{H}_{2} \mathrm{PO}_{4}$ was accompanied by the generation of ammonia gas $\left(\mathrm{NH}_{3}\right)$, which induced slight bubbling. However, such slight bubbling would not cause sever volume expansion, according to the results of the control group shown in Figure 2a. Obviously, the limestone fines intensified the bubbling effect. It was inferred that $\mathrm{CaCO}_{3}$ as the main content of limestone fines could react with $\mathrm{NH}_{4} \mathrm{H}_{2} \mathrm{PO}_{4}$ to form $\mathrm{NH}_{4} \mathrm{HCO}_{3}$, which was unstable at a temperature over $36^{\circ} \mathrm{C}$ and decomposed into $\mathrm{NH}_{3}$ and $\mathrm{CO}_{2}$. Meanwhile, the limestone fines may act as the catalyst accelerating the hydration of MAPC. Therefore, intensified gas generation resulted in dramatic volume expansion before hardening. 


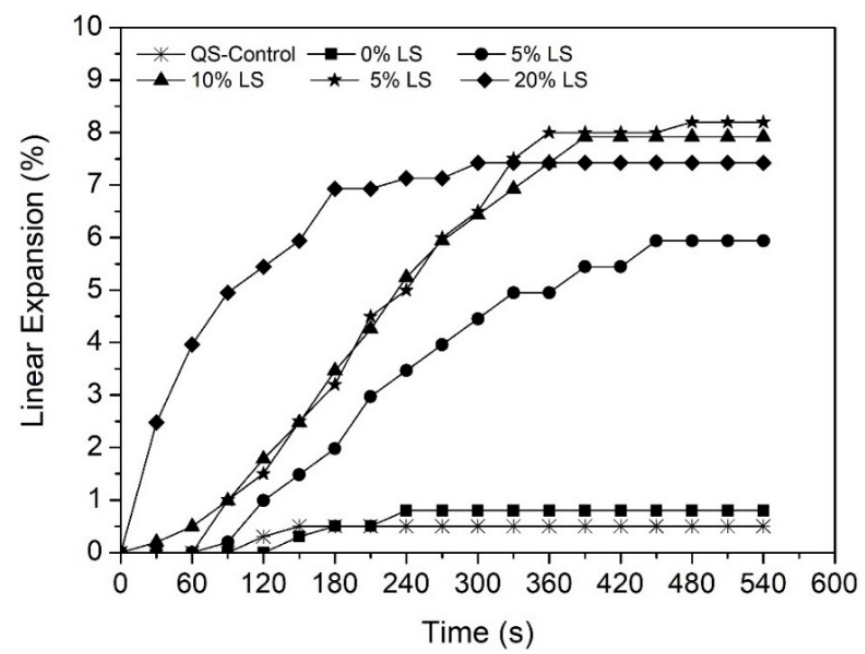

(a)

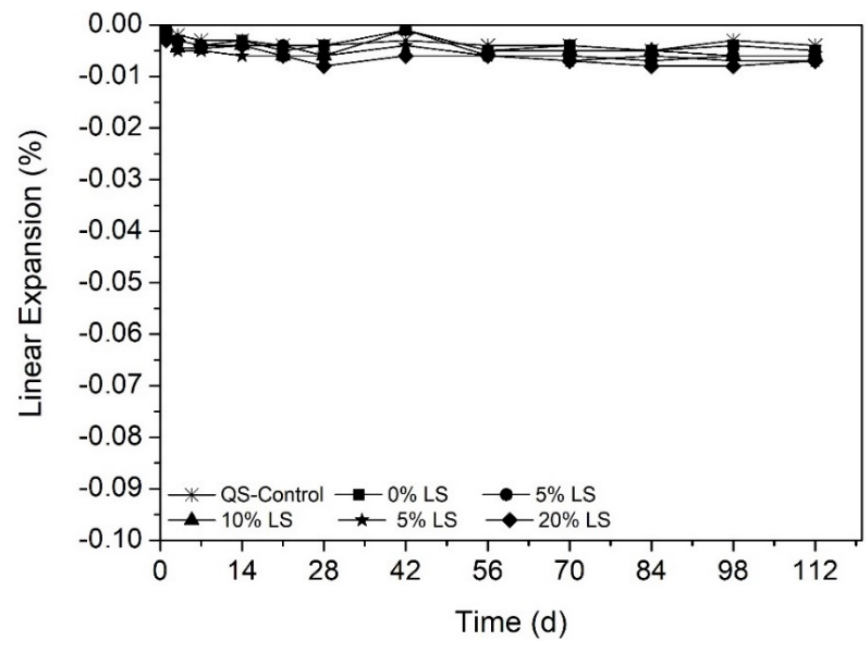

(b)

Figure 4. Linear expansion of MAPC mortar samples (a) before setting and (b) after setting; where the QS-Control refers to the sample prepared by quartz sand and 0 to $20 \%$ LS refers to samples prepared by limestone sand containing different contents of limestone fines ranging from 0 to $20 \%$ by weight of MAPC cement.

After hardening, the volume of all groups became very stable at a later age and only showed a slight shrinkage of less than $0.01 \%$, as shown in Figure $4 \mathrm{~b}$. It seems that the limestone fines affected only the volume stability of MAPC mortar at an early age before hardening.

\subsection{Hydration Temperature of $M A P C$}

The evolution of hydration temperature inside MAPC mortar samples during early age is shown in Figure 5. The hydration of MAPC is an intense exothermic process during which the internal temperature rises rapidly and peaks at around $80{ }^{\circ} \mathrm{C}$ within the first 30 min after mixing. MAPC samples with limestone fines reached the temperature peak faster than the control, implying that the incorporation of limestone fines accelerated the hydration of MAPC. Furthermore, such an acceleration effect became more pronounced as the content of limestone fines increased. In particular, at content over $10 \%$, the temperature peaks obviously moved forward. This explained the shortened setting time at a high content of limestone fines as observed in Figure 1b. The accelerated hydration can be due to the intense bubbling reaction between limestone fines and MAPC components at an early age as reported above in 3.2. $\mathrm{As}_{\mathrm{CaCO}_{3}}$ from limestone fines reacts with ADP to 
generate gases, the consumption of ADP was supposed to also promote the hydration of MAPC itself. This acceleration effect on the hydration of MAPC is further investigated by microstructure analysis.

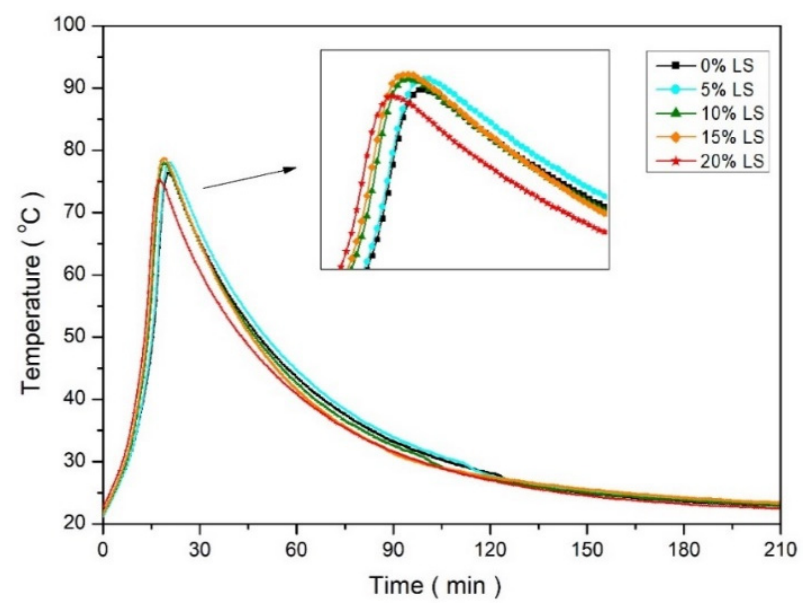

Figure 5. The evolution of hydration temperature of MAPC mortar samples with different contents of limestone fines ( $0-20 \%$ by weight of MAPC cement).

\subsection{Mechanical Strength of MAPC}

The limestone fines content showed to have a significant effect on the mechanical strength of MAPC mortar. In Figure 6a, the trends showed that compressive strength decreased with increasing limestone fines content, which were observed at all test ages. The negative effect of limestone fines on compressive strength was more pronounced with later age. Limestone fines at content of $20 \%$ caused a decrease of $17.1 \%$ in compressive strength at an early age of $1 \mathrm{~h}$, and an even higher decrease of $31.8 \%$ at a later age of 28 days. The decrease of compressive strength can be due to the bubbling reaction before hardening caused by limestone stone fines as reported in Section 3.1. It was inferred that the bubbling increased the porosity of the MAPC matrix, thus decreasing the compressive strength. The compressive strength was reported to be largely dependent on the porosity of cementitious structures. There are a number of well-established strength versus porosity relationships, which describe the negative impacts of a loose pore system on concrete strength [26-31]. Similarly, the flexural strength generally decreased with increasing limestone fines content, especially at a later age (Figure $6 \mathrm{~b}$ ). The limestone fines at a content of $20 \%$ caused a flexural strength loss of $19.8 \%$ and $18.7 \%$ at ages of 3 days and 28 days, respectively.

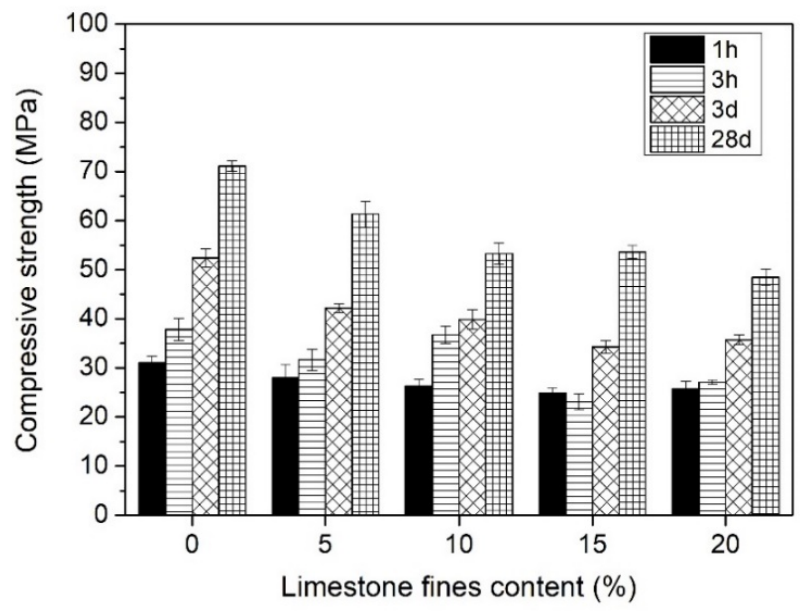

(a)

Figure 6. Cont. 


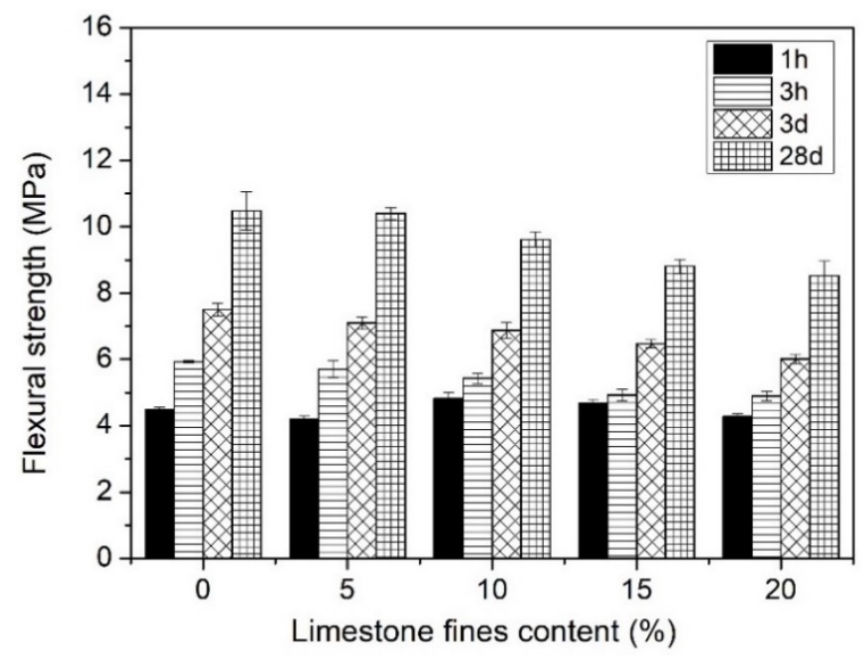

(b)

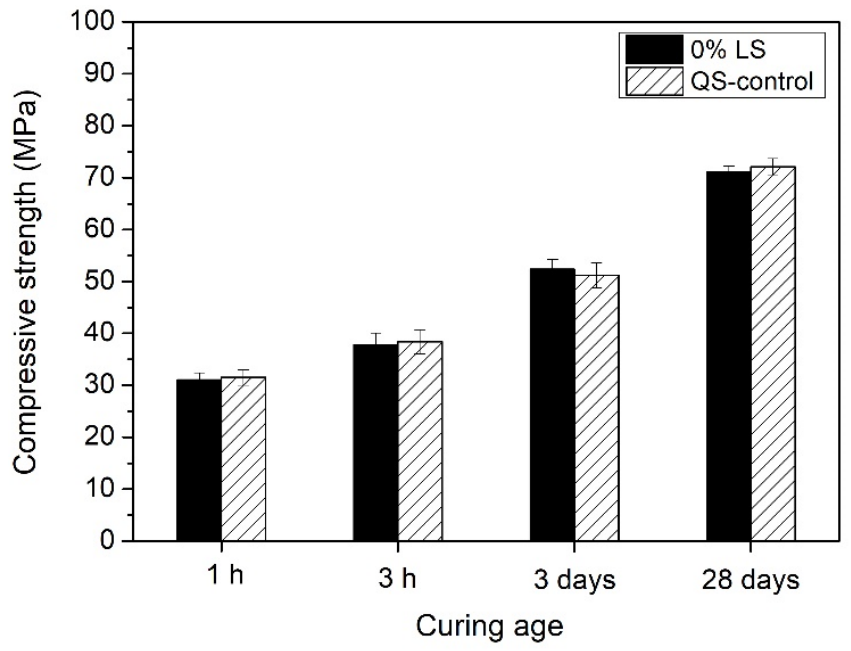

(c)

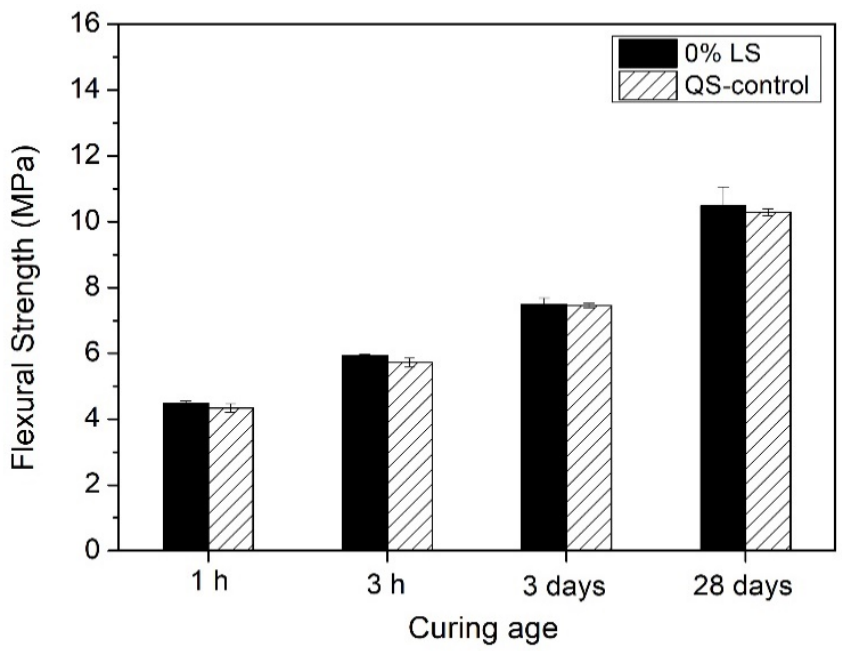

(d)

Figure 6. (a) Compressive strength and (b) flexural strength of MPAC mortar with limestone fines at different contents of 0-20\%; (c) compressive strength and (d) flexural strength of MAPC mortar prepared by quartz sand or limestone sand without limestone fines. 
Without the influence of limestone fines, there is no significant change with the strength of MAPC mortar. As shown in Figure $6 c, d$, MAPC mortar prepared by limestone sand with $0 \%$ limestone fines generally maintained the same level of compressive strength and flexural strength as the control sample prepared by quartz sand.

\subsection{Microstructure Analysis}

- $\quad$ MIP

The effects of limestone fines on the microstructure of MAPC mortar were analyzed by MIP tests. As shown in Figure 7a, the total porosity of MAPC mortar samples significantly increased with the increasing content of limestone fines. The sample without limestone fines showed a total porosity of $15.39 \%$. At a content of $20 \%$ limestone fines, the total porosity increased to $26.16 \%$.

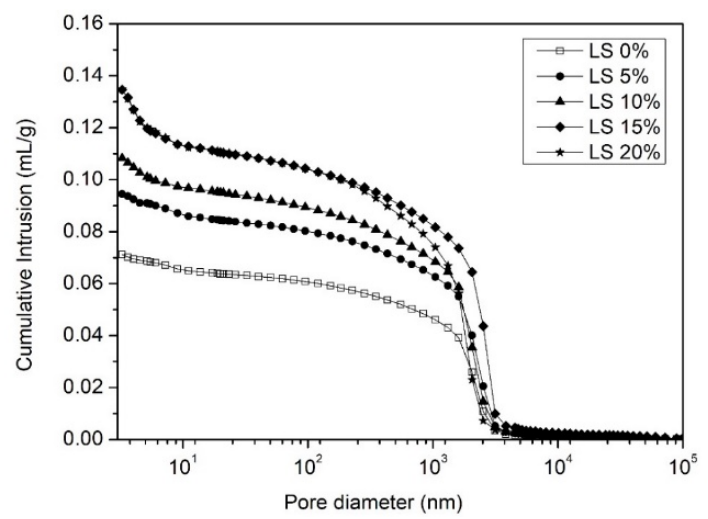

(a)

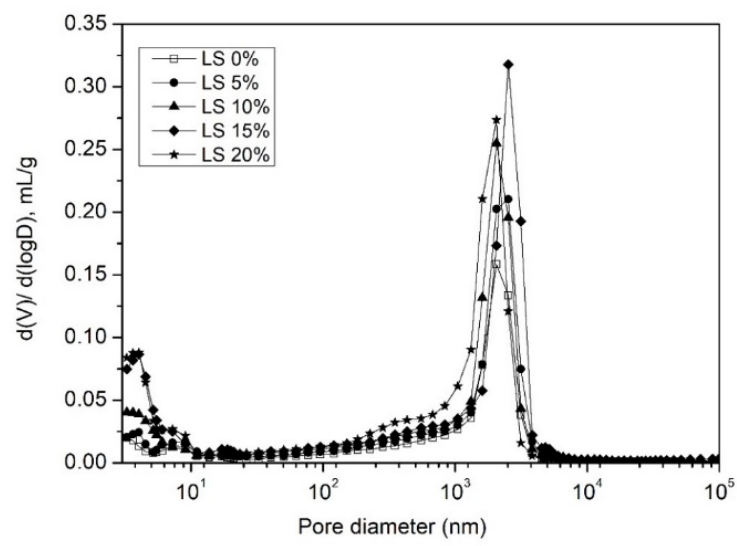

(b)

Figure 7. Mercury intrusion porosimetry results on MAPC mortar with limestone fines at different contents of 0-20\%: (a) Cumulative intrusion and (b) pore size distribution.

Evidently, the increased porosity was attributed to the intense bubbling induced by limestone fines. Masses of bubbles expanded the fresh mixes before hardening and remained as macropores in the hardened matrix, thus loosening the structure of MAPC samples. According to results on the pore size distribution in Figure $7 \mathrm{~b}$, the interior pores of MAPC mortar are mainly micropores smaller than $10 \mathrm{~nm}$ and macropores around $1 \mu \mathrm{m}$. The pore system in cement-based materials consists of four types of pores, including micropores with an average size less than $10 \mathrm{~nm}$; capillary pores which are mesopores with an average size ranging from 5 to $5000 \mathrm{~nm}$; and macropores due to deliberately entrained air and macropores due to inadequate compaction [26,28,31]. Capillary pores and other larger macropores are responsible for reduction in strength. Normally, pores larger than $200 \mathrm{~nm}$ are considered harmful to the compressive strength of the cementitious matrix [28,31]. 
The bubbling caused by limestone fines significantly increased those harmful macropores, which were very likely to be the weak points for cracking under loading. Increasing porosity can also lead to decreased impermeability, which is detrimental to long-term durability [32]. The MIP results above explained the reduced strength of MAPC mortar samples as increasing the content of limestone fines.

- TGA

Figure 8 presents the thermogravimetric traces of MAPC mortar samples at different ages of $1 \mathrm{~h}, 3$ days, and 28 days, respectively. For control samples without limestone fines, two main peaks can be observed in the DTG curves shown in Figure 8a. The mass loss for each decomposition phase was summarized in Table 1 . The first peak at a temperature range from $60{ }^{\circ} \mathrm{C}$ to $150{ }^{\circ} \mathrm{C}$ denoted the decomposition of struvite $\left(\mathrm{NH}_{4} \mathrm{MgPO}_{4} \cdot 6 \mathrm{H}_{2} \mathrm{O}\right)$ by the release of its chemically bond water [33,34]. The initial mass loss at $50 \sim 60{ }^{\circ} \mathrm{C}$ could be due to the release of absorbed water from the finery sample since the sample could not be absolutely dry. At a temperature over $60^{\circ} \mathrm{C}$, struvite started to decompose into dittmarite $\left(\mathrm{MgNH}_{4} \mathrm{PO}_{4} \cdot \mathrm{H}_{2} \mathrm{O}\right)$ and eventually transformed into $\mathrm{Mg}_{2} \mathrm{P}_{2} \mathrm{O}_{7}$ accompanied by the release of $\mathrm{H}_{2} \mathrm{O}$ and $\mathrm{NH}_{3}$ [35]. In Figure $8 \mathrm{~b}$, it is evident that the mass loss of control samples increased with curing age from $6.98 \%$ to $12.80 \%$ during this stage, indicating the accumulation of struvite as the hydration proceeded. In the following temperature range from $150{ }^{\circ} \mathrm{C}$ to $300^{\circ} \mathrm{C}$, the second peak could be mainly attributed to the decomposition of unreacted $\mathrm{NH}_{4} \mathrm{H}_{2} \mathrm{PO}_{4}$ (ADP) which was more intense at an early age of $1 \mathrm{~h}$ and 3 days.

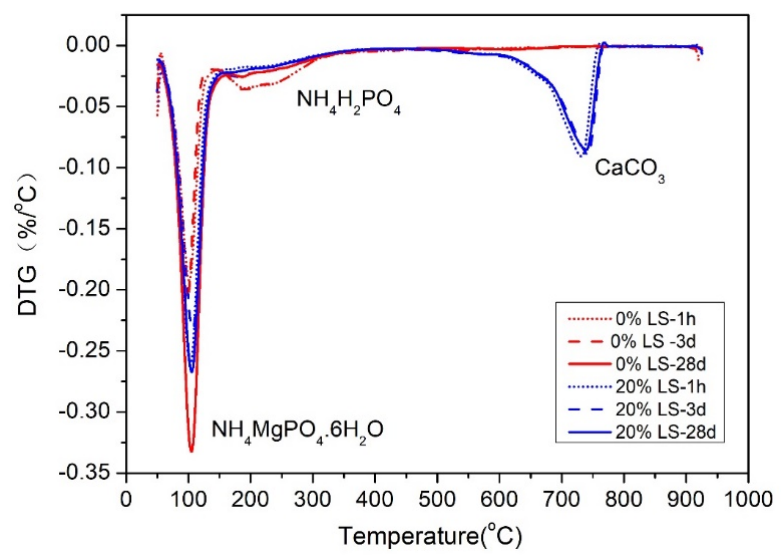

(a)

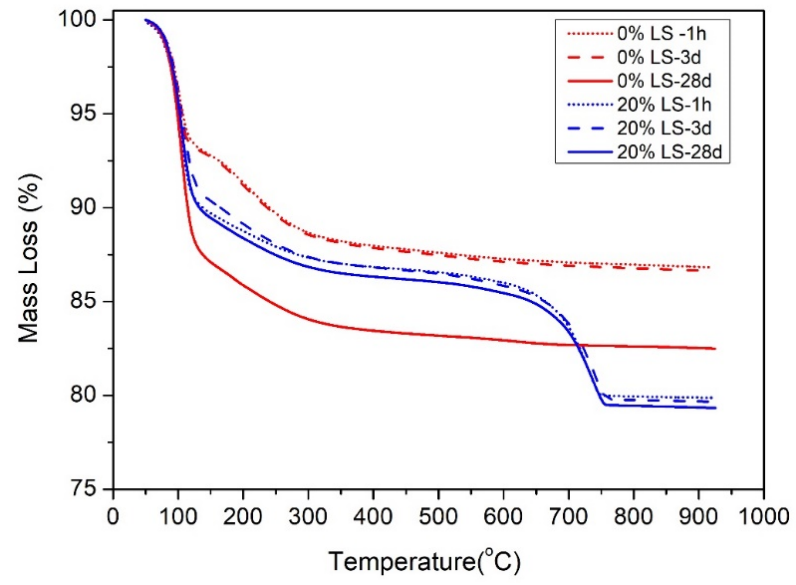

(b)

Figure 8. Thermogravimetric (TGA) analysis on MAPC mortar samples with $0 \%$ and $20 \%$ limestone fines at different curing ages of 1 h, 3 days, and 28 days, (a) differential thermogravimetry (DTG) curves; (b) mass loss curves. 
Table 1. The mass loss (\%) for main decomposition phases of MAPC mortar samples with $0 \%$ and $20 \%$ limestone fines at different curing ages of $1 \mathrm{~h}, 3$ days, and 28 days according to thermogravimetric (TGA) results.

\begin{tabular}{cccc}
\hline Sample & $\begin{array}{c}\text { Phase } \mathbf{1} \\
\text { (Temperature Range } \\
\left.\mathbf{6 0 - 1 5 0}{ }^{\circ} \mathbf{C}\right)\end{array}$ & $\begin{array}{c}\text { Phase 2 } \\
(\text { Temperature Range } \\
\left.\mathbf{1 5 0 - 3 0 0}{ }^{\circ} \mathbf{C}\right)\end{array}$ & $\begin{array}{c}\text { Phase 3 } \\
\text { (Temperature Range } \\
\left.\mathbf{7 0 0 - 7 6 0}{ }^{\circ} \mathbf{C}\right)\end{array}$ \\
\hline 0\% LS-1 h & 6.98 & 4.22 & $/$ \\
\hline $0 \%$ LS-3 d & 7.08 & 4.02 & $/$ \\
\hline 0\% LS-28 d & 12.80 & 3.00 & 6.19 \\
\hline 20\% LS-1 h & 9.47 & 2.93 & 6.24 \\
\hline 20\% LS-3 d & 10.09 & 2.33 & 6.38 \\
\hline 20\% LS-28 d & 10.40 & 2.01 & \\
\hline
\end{tabular}

By contrast, MAPC samples containing $20 \%$ limestone fines yielded three main peaks throughout the thermal process. Apart from the first two peaks for struvite and ADP, a third peak at a temperature range from $600{ }^{\circ} \mathrm{C}$ to $760^{\circ} \mathrm{C}$ that represented the decomposition of $\mathrm{CaCO}_{3}$ was detected. It was surprisingly found that all three samples with $20 \%$ limestone fines at a different age showed only minor variations in mass loss at this peak, indicating that very few $\mathrm{CaCO}_{3}$ was further consumed by reaction with ADP after $1 \mathrm{~h}$. The mass loss caused by $\mathrm{CaCO}_{3}$ decomposition at different age ranges from $6.19 \%$ to $6.38 \%$, based on which content of $\mathrm{CaCO}_{3}$ in the MAPC sample could be roughly calculated as $14.5 \%$. According to the mix proportion, the content of limestone fines in the mixture of reactants was $16.7 \%$. It could be inferred that the reaction between $\mathrm{CaCO}_{3}$ and $\mathrm{ADP}$ mainly occurred at a very early age before hardening and only a small percentage of $\mathrm{CaCO}_{3}$ around $2.2 \%$ was consumed during this reaction.

Meanwhile, compared with the control samples at an early age of $1 \mathrm{~h}$ and 3 days, MAPC samples containing limestone fines at the same age had a higher mass loss during the main decomposition stage of struvite, as shown in Table 1. It is evident that MAPC samples hydrated faster with the presence of limestone fines, which confirmed the acceleration effect on MAPC hydration as aforementioned by results on the hydration temperature in Figure 5.

\section{- $\quad$ XRD}

Figure 9 shows the XRD results on MAPC samples at a curing age of 28 days. Similar diffraction peaks of struvite distributed throughout the spectrum were identified in both samples with and without limestone fines. In particular, the peaks of calcite (mainly at $2 \theta=29.6^{\circ}$ ) were detected in the samples with limestone fines whereas the similar peaks were absent in the control samples. Meanwhile, several small peaks of $\mathrm{CaHPO}_{4}\left(\right.$ at $2 \theta=26^{\circ}$, $30.7^{\circ}, 48.6^{\circ}$ ) were also detected in the samples with limestone fines. This confirmed the assumption on the reaction between $\mathrm{CaCO}_{3}$ and $\mathrm{ADP}$ which generated $\mathrm{CaHPO}_{4}$ together with $\mathrm{CO}_{2}$ and $\mathrm{NH}_{3}$ gases. As reflected by the TGA results, this reaction mainly occurred at a very early age before hardening and consumed only a small percentage of $\mathrm{CaCO}_{3}$. Correspondingly, only a few weak peaks of $\mathrm{CaHPO}_{4}$ as the reaction products were observed in the spectrum curve. There were still intense peaks for unreacted $\mathrm{CaCO}_{3}$ identified in MAPC samples with limestone fines. 


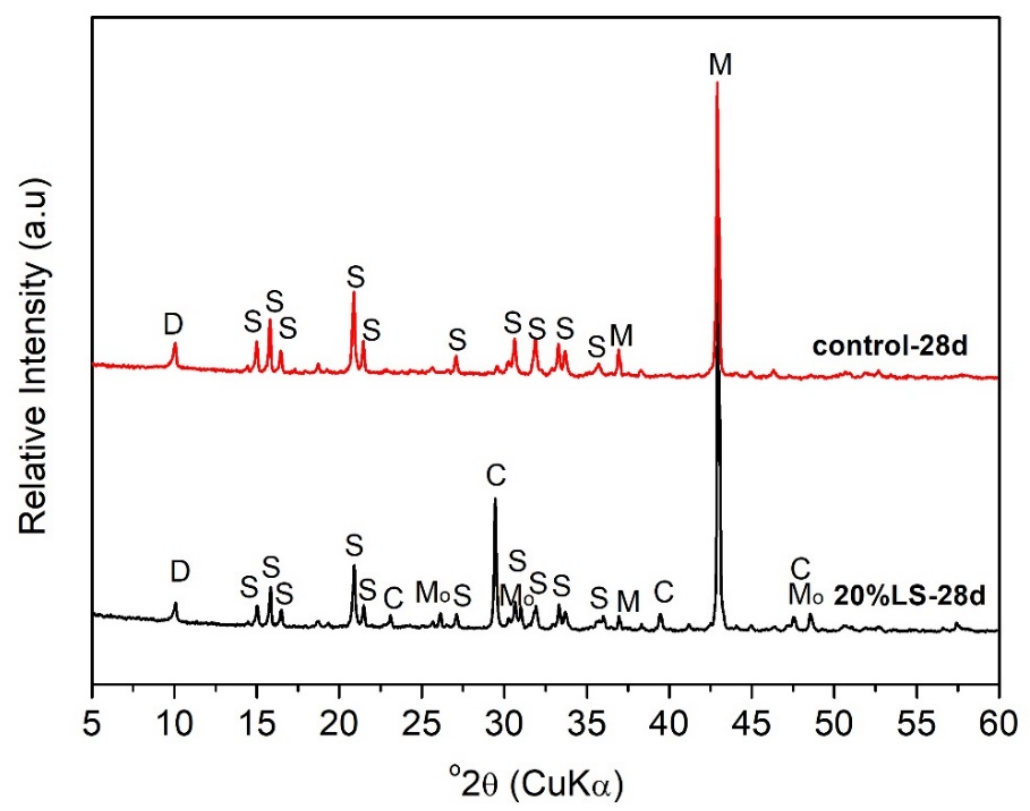

Figure 9. X-ray diffraction (XRD) spectrum for MAPC samples containing 20\% limestone fines at a curing age of 28 days, where C: Calcite (PDF \#00-005-0586), D: Dittmarite $\left(\mathrm{MgNH}_{4} \mathrm{PO}_{4} \cdot \mathrm{H}_{2} \mathrm{O}\right)(\mathrm{PDF}$ \#20-663), M: Magnesium Oxide (MgO) (PDF \#45-0946), Mo: Monetite (CaHPO 4 ) (PDF\# 09-0080), and S: Struvite $\left(\mathrm{NH}_{4} \mathrm{MgPO}_{4} \cdot 6 \mathrm{H}_{2} \mathrm{O}\right)(\mathrm{PDF} \# 15-0762)$.

\section{- SEM}

The overviews of the surface morphology of MAPC mortar samples are shown in Figure $10 \mathrm{a}, \mathrm{b}$. The sample with $20 \%$ limestone fines is obviously more porous than the one without limestone fines due to the bubbling reaction, which is consistent with MIP results. The limestone sands were also observed randomly distributing in the MAPC mortar. Despite the porous structure, hydrated MAPC pastes showed close bonding with the limestone sand particles. A closer observation of the bonding interface shows that the sand particles were surrounded by MAPC hydration products without obvious pore formation at the interface (Figure 10c). Unlike limestone fines, the limestone sands seemed unreactive to ADP in MAPC system. $\mathrm{CaCO}_{3}$ in the form of micro-sized particles $(<0.075 \mathrm{~mm})$ was considered the reactive one causing bubbling reaction with ADP. As the view turned to the hydration products, clusters of lamellar struvite crystals spread over the MAPC mortar matrix. Among the struvite clusters, micro-sized limestone fines were recognized as parallel rhombohedrons (calcite) with small clumps of crystals growing on their surface (Figure 10d). According to the EDX analysis, those small crystals contained calcium, phosphorus, oxygen, and nitrogen as their main chemical elements. The small crystals were therefore verified as the reaction products of $\mathrm{CaCO}_{3}$ and $\mathrm{ADP} . \mathrm{NH}_{4} \mathrm{HCO}_{3}$ is instable and prone to decompose at a temperature over $30^{\circ} \mathrm{C}$ as aforementioned. These reaction products therefore mainly consisted of $\mathrm{CaHPO}_{4}$. Due to the fast but short reaction period, there were only small quantities of $\mathrm{CaHPO}_{4}$ with a poor crystal shape formed on the surface of limestone fines. The major parts of limestone crystals remained in their original state in the MAPC matrix. The above results confirmed the effects of limestone fines on MAPC mortar by increasing its porosity as well as the mechanism behind such effects from the microstructure point. 


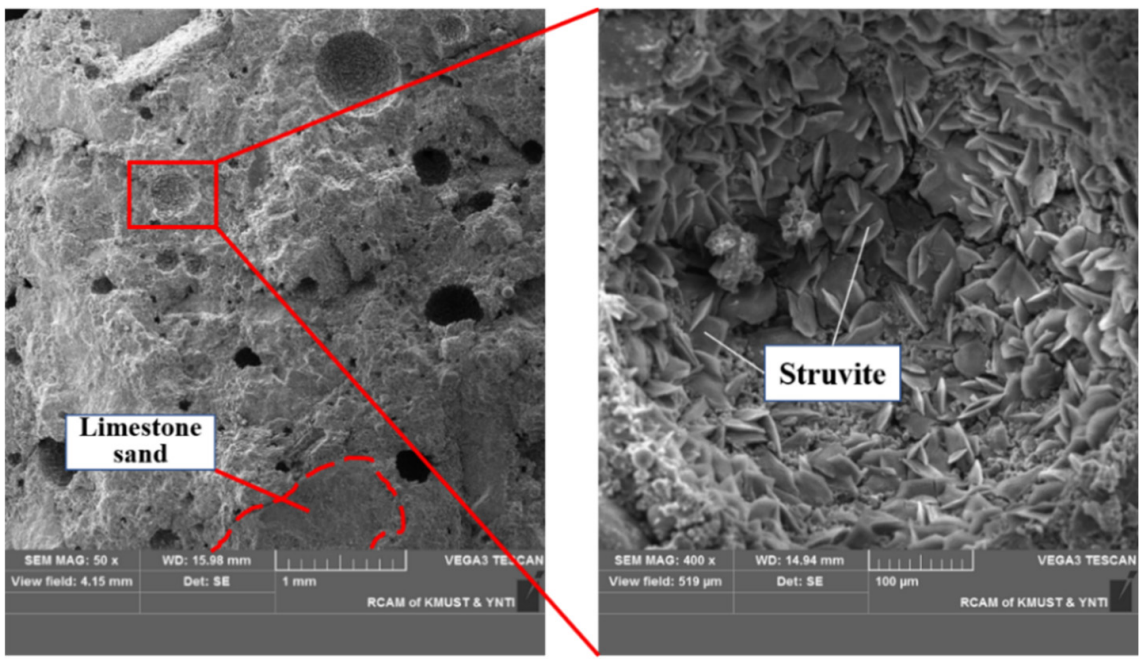

(a)

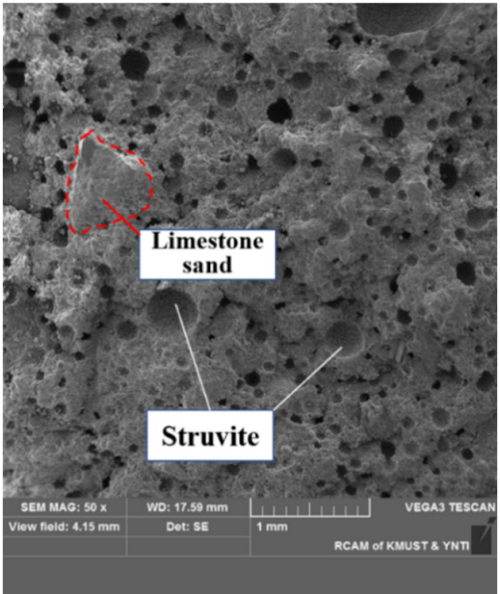

(b)

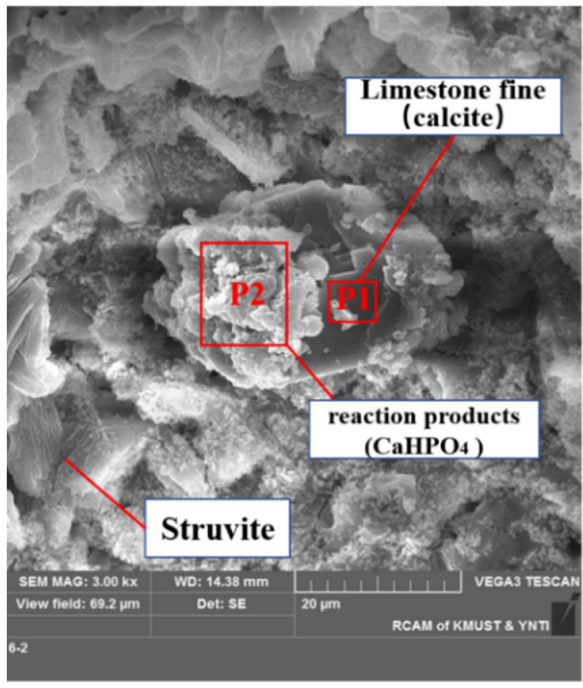

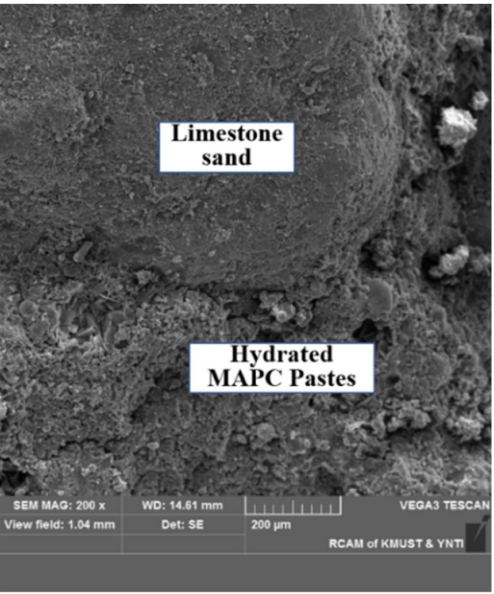

(c)
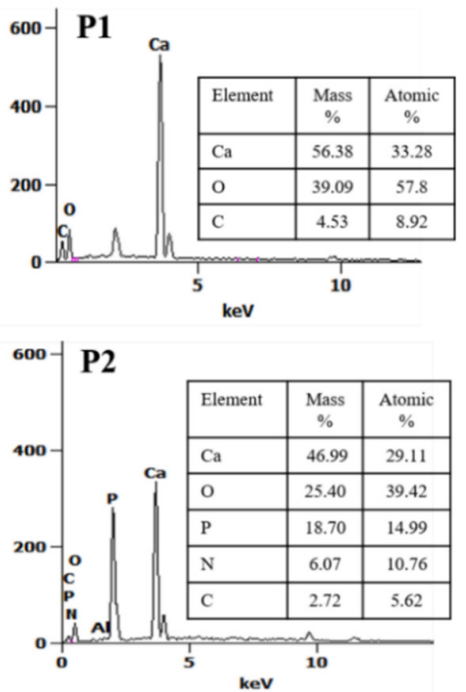

(d)

Figure 10. SEM observations of MAPC mortar samples with different contents of limestone fines (a) limestone fines at content of $0 \%$; (b) limestone fines at content of $20 \%$; (c) bonding interface between limestone sand and MAPC pastes; and (d) SEM image of limestone fine and its reaction products with ADP, and the corresponding EDX analysis results. 


\title{
4. Conclusions
}

This paper presented experimental findings on the effects of limestone fines of manufactured sand on properties of MAPC mortar. The conclusions from this research work can be drawn as follows:

1. Limestone fines are the key factor that influences the properties of MAPC mortar. The MAPC mortar prepared by manufactured sands without limestone fines showed comparable properties with the one prepared by quartz sands.

2. The limestone fines $(<0.075 \mathrm{~mm})$ of manufactured sands caused an intense bubbling phenomenon and significant volume expansion in the system of MAPC before hardening. The higher the content of limestone fines, the larger the volume expansion. It is noted that the volume expansion occurred only before hardening while the volume of hardened MAPC mortar remained stable in the long term.

3. As the content of limestone fines increased, the MAPC mortar showed decreased fluidity. The limestone fines also showed an acceleration effect on the hydration of MAPC mortar at early age. As a result, the setting time of MAPC mortar became shorter, especially with a higher content $(>15 \%)$ of limestone fines. TGA results confirmed that more struvite was generated in MAPC mortar with limestone fines.

4. The limestone fines showed significant negative effects on the mechanical strength of MAPC mortar, especially for the compressive strength. As the content of limestone fines increased from 0 to $20 \%$, the compressive strength at 28 days decreased by $31.8 \%$. By contrast, the development of flexural strength was less affected by the limestone fines.

5. According to MIP results, the incorporation of limestone fines led to increased porosity of MAPC mortar due to the bubbling reaction, thus decreasing the mechanical strength.

6. Based on the microstructure analysis, including TGA, XRD, and SEM, it is inferred that the bubbling phenomenon was mainly caused by the reaction between limestone fines $\left(\mathrm{CaCO}_{3}\right)$ and $\mathrm{NH}_{4} \mathrm{H}_{2} \mathrm{PO}_{4}(\mathrm{ADP})$, which generated $\mathrm{NH}_{3}$ and $\mathrm{CO}_{2}$ gases. This reaction mainly occurred during a short period before setting. Most limestone fines were not involved in the hydration process of MAPC and remained unreactive in the hardened MAPC matrix.

In conclusion, the effects of manufactured sands on MAPC mortar mainly originate from the bubbling reaction caused by limestone fines during the period before setting. For the utilization of manufactured limestone sands in the preparation of MAPC mortar, feasible methods, such as defoaming agents, can be further tested for the inhibition of bubbling.

\begin{abstract}
Author Contributions: Conceptualization, W.M.; methodology, W.M.; software, W.M. and C.C.; validation, W.M. and C.C.; formal analysis, W.M.; investigation, W.M. and C.C.; resources, W.M., J.Q. and Y.D.; data curation, W.M. and C.C.; writing-original draft preparation, W.M.; writing-review and editing, W.M. and X.L.; visualization, W.M.; supervision, X.L. and J.Q.; project administration, W.M. and X.L.; funding acquisition, X.L., W.M. and Y.D. All authors have read and agreed to the published version of the manuscript.
\end{abstract}

Funding: This research was funded by Yunnan Province Science and Technology Projects, grant number 202004AR040017; 202001AU070069. The APC was funded by Yunnan Academy of Building Research Co., Ltd.

Acknowledgments: The support for this research work from the Yunnan Province Science and Technology Department is gratefully acknowledged.

Conflicts of Interest: The authors declare no conflict of interest.

\section{References}

1. Walling, S.A.; Provis, J.L. Magnesia-Based Cements: A Journey of 150 Years, and Cements for the Future? Chem. Rev. 2016, 116, 4170-4204. [CrossRef] [PubMed]

2. Xiao, J.; Long, X.; Qu, W.; Li, L.; Jiang, H.; Zhong, Z. Influence of sulfuric acid corrosion on concrete stress-strain relationship under uniaxial compression. Measurement 2021, 187, 110318. [CrossRef]

3. Wang, L.; Guo, F.X.; Yang, H.M.; Wang, Y.; Tang, S.W. Comparison of FLY ASH, PVA Fiber, MgO and Shrinkage-reducing Admixture on the Frost Resistance of Face Slab Concrete via Pore Structural and Fractal Analysis. Fractals 2021, 29, 2140002. [CrossRef] 
4. Haque, M.A.; Chen, B. Research progresses on magnesium phosphate cement: A review. Constr. Build. Mater. 2019, 211, 885-898. [CrossRef]

5. Qian, J. 4-Magnesium Phosphate Cement; Shand, M.A., Al-Tabbaa, A., Qian, J., Mo, L., Jin, F., Cements, M., Eds.; Elsevier: Amsterdam, The Netherlands, 2020; pp. 85-170, ISBN 9780123919250. [CrossRef]

6. Yang, N.; Shi, C.; Yang, J.; Chang, Y. Research Progresses in Magnesium Phosphate Cement—Based Materials. J. Mater. Civ. Eng. 2014, 26, 04014071. [CrossRef]

7. You, C.; Qian, J.; Qin, J.; Wang, H.; Wang, Q.; Ye, Z. Effect of early hydration temperature on hydration product and strength development of magnesium phosphate cement (MPC). Cem. Concr. Res. 2015, 78, 179-189. [CrossRef]

8. Qin, J.; Qian, J.; You, C.; Fan, Y.; Li, Z.; Wang, H. Bond behavior and interfacial micro-characteristics of magnesium phosphate cement onto old concrete substrate. Constr. Build. Mater. 2018, 167, 166-176. [CrossRef]

9. Abdelrazig, B.; Sharp, J.; El-Jazairi, B. The chemical composition of mortars made from magnesia-phosphate cement. Cem. Concr. Res. 1988, 18, 415-425. [CrossRef]

10. Ma, C.; Wang, F.; Zhou, H.; Jiang, Z.; Ren, W.; Du, Y. Effect of early-hydration behavior on rheological properties of borax-admixed magnesium phosphate cement. Constr. Build. Mater. 2021, 283, 122701. [CrossRef]

11. Yang, Q.; Wu, X. Factors influencing properties of phosphate cement-based binder for rapid repair of concrete. Cem. Concr. Res. 1999, 29, 389-396. [CrossRef]

12. Qiao, F.; Chau, C.; Li, Z. Property evaluation of magnesium phosphate cement mortar as patch repair material. Constr. Build. Mater. 2010, 24, 695-700. [CrossRef]

13. Wang, Q.; Qian, J.; Qin, J.; You, C.; Wang, H. Effect of ambient temperature on setting time and strength development of magnesia-phosphate cement. J. Chin. Ceram. Soc. 2013, 41, 1493-1498. (In Chinese). Available online: https://kns.cnki.net/kcms/ detail $/$ detail.aspx?dbcode=CJFD\&dbname=CJFDHIS2\&filename=GXYB201311006\&uniplatform=NZKPT\&v=DV39cad9uxp6 EkVAelxgLK4gk8cOA5MNqWilIORI03BA9NJTpZ1V7a6e5ZZ41\%25mmd2BUv (accessed on 25 December 2021).

14. Le Rouzic, M.; Chaussadent, T.; Stefan, L.; Saillio, M. On the influence of $\mathrm{Mg} / \mathrm{P}$ ratio on the properties and durability of magnesium potassium phosphate cement pastes. Cem. Concr. Res. 2017, 96, 27-41. [CrossRef]

15. Chauhan, C.K.; Vyas, P.M.; Joshi, M.J. Growth and characterization of Struvite-K crystals. Cryst. Res. Technol. 2011, 46, 187-194. [CrossRef]

16. Wang, D.; Shi, C.; Farzadnia, N.; Shi, Z.; Jia, H. A review on effects of limestone powder on the properties of concrete. Constr. Build. Mater. 2018, 192, 153-166. [CrossRef]

17. Liu, S.; Yan, P. Effect of limestone powder on microstructure of concrete. J. Wuhan Univ. Technol. Sci. Ed. 2010, 25, 328-331. [CrossRef]

18. Wang, L.; Lu, X.; Liu, L.; Xiao, J.; Zhang, G.; Guo, F.; Li, L. Influence of MgO on the Hydration and Shrinkage Behavior of Low Heat Portland Cement-Based Materials via Pore Structural and Fractal Analysis. Fractal Fract. 2022, 6, 40. [CrossRef]

19. Yang, J.; Du, B.; Xu, X. Effect of limestone powder on properties of magnesium phosphate cement paste. J. Build. Mater. 2015, 18, 34-38. (In Chinese) [CrossRef]

20. Chong, L.; Shi, C.; Yang, J.; Jia, H. Effect of limestone powder on the water stability of magnesium phosphate cement-based materials. Constr. Build. Mater. 2017, 148, 590-598. [CrossRef]

21. ASTM C939-10; Standard Test Method for Flow of Grout for Preplaced-Aggregate Concrete (Flow Cone Method). ASTM International: West Conshohocken, PA, USA, 2010.

22. ASTMC187-10; Standard Test Method for Normal Consistency of Hydraulic Cement. ASTM International: West Conshohocken, PA, USA, 2010.

23. ISO 679:2009; Cement-Test Methods-Determination of Strength. ISO/TC 74. 2009. Available online: https://standards.iteh.ai/ catalog/standards/iso/12357ab7-763f-4e77-80f4-8faba1f901b5/iso-679-2009 (accessed on 11 January 2022).

24. JTG 3420-2020 (T 0518-2020); Testing Methods of Cement and Concrete for Highway Engineering: Testing Method for Free Bleeding Rate and Free Expansion Rate of Cement Slurry. Ministry of Transport of the People's Republic of China: Beijing, China, 2020.

25. ASTM C596-18; Standard Test Method for Drying Shrinkage of Mortar Containing Hydraulic Cement. ASTM International: West Conshohocken, PA, USA, 2018.

26. Kumar, R.; Bhattacharjee, B. Porosity, pore size distribution and in situ strength of concrete. Cem. Concr. Res. 2003, 33, 155-164. [CrossRef]

27. Kearsley, E.P.; Wainwright, P.J. The effect of porosity on the strength of foamed concrete. Cem. Concr. Res. 2002, 32, 233-239. [CrossRef]

28. Huang, J.; Li, W.; Huang, D.; Wang, L.; Chen, E.; Wu, C.; Wang, B.; Deng, H.; Tang, S.; Shi, Y.; et al. Fractal Analysis on Pore Structure and Hydration of Magnesium Oxysulfate Cements by First Principle, Thermodynamic and Microstructure-Based Methods. Fractal Fract. 2021, 5, 164. [CrossRef]

29. Wang, L.; Zeng, X.; Yang, H.; Lv, X.; Guo, F.; Shi, Y.; Hanif, A. Investigation and Application of Fractal Theory in Cement-Based Materials: A Review. Fractal Fract. 2021, 5, 247. [CrossRef]

30. Vu, V.-H.; Tran, B.-V.; Le, B.-A.; Nguyen, H.-Q. Prediction of the relationship between strength and porosity of pervious concrete: A micromechanical investigation. Mech. Res. Commun. 2021, 118, 103791. [CrossRef]

31. Lian, H.; Shi, H. Clarification of a Hypothesis on'Centroplasm of Cement-based Composite' Proposed by Wu Zhongwei. J. Chin. Ceram. Soc. 2020, 48, 777. [CrossRef]

32. Wang, L.; Song, X.; Yang, H.; Wang, L.; Tang, S.; Wu, B.; Mao, W. Pore structural and fractal analysis of the effects of MgO reactivity and dosage on permeability and F-T resistance of concrete. Fractal Fract. 2022, 6, 113. [CrossRef] 
33. Bhuiyan, M.I.H.; Mavinic, D.; Koch, F. Thermal decomposition of struvite and its phase transition. Chemosphere 2008, 70, 1347-1356. [CrossRef]

34. Paul, I.; Varghese, G.; Ittayachen, M.A. Thermal decomposition studies of struvites. Indian J. Pure Appl. Sci. $2002,40,664-669$.

35. Ramlogan, M.V.; Rouff, A.A. An investigation of the thermal behavior of magnesium ammonium phosphate hexahydrate. J. Therm. Anal. 2016, 123, 145-152. [CrossRef] 